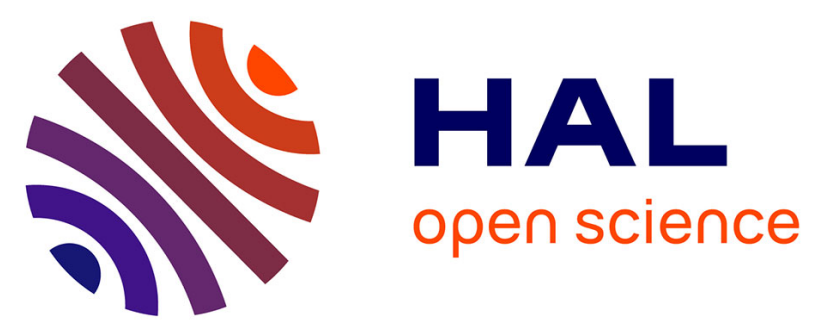

\title{
An experimental and modeling study of ammonia with enriched oxygen content and ammonia/hydrogen laminar flame speed at elevated pressure and temperature
}

Krishna Prasad Shrestha, Charles Lhuillier, Amanda Alves Barbosa, Pierre Brequigny, Francesco Contino, Christine Mounaïm-Rousselle, Lars Seidel, Fabian Mauss

\section{To cite this version:}

Krishna Prasad Shrestha, Charles Lhuillier, Amanda Alves Barbosa, Pierre Brequigny, Francesco Contino, et al.. An experimental and modeling study of ammonia with enriched oxygen content and ammonia/hydrogen laminar flame speed at elevated pressure and temperature. Proceedings of the Combustion Institute, 2020, 38 (2), pp.2163-2174. 10.1016/j.proci.2020.06.197 . hal-02934520

\author{
HAL Id: hal-02934520 \\ https://hal.science/hal-02934520
}

Submitted on 9 Sep 2020

HAL is a multi-disciplinary open access archive for the deposit and dissemination of scientific research documents, whether they are published or not. The documents may come from teaching and research institutions in France or abroad, or from public or private research centers.
L'archive ouverte pluridisciplinaire HAL, est destinée au dépôt et à la diffusion de documents scientifiques de niveau recherche, publiés ou non, émanant des établissements d'enseignement et de recherche français ou étrangers, des laboratoires publics ou privés. 
An experimental and modeling study of ammonia with enriched oxygen content and ammonia/hydrogen laminar flame speed at elevated pressure and temperature

Krishna Prasad Shrestha ${ }^{1}$, Charles Lhuillier ${ }^{2,3}$, Amanda Alves Barbosa ${ }^{2}$, Pierre Brequigny ${ }^{2}$,

Francesco Contino $^{3}$, Christine Mounaïm-Rousselle ${ }^{2}$, Lars Seidel ${ }^{4 *}$, Fabian Mauss $^{1}$

1. Thermodynamics and Thermal Process Engineering, Brandenburg University of Technology, Siemens-Halske-Ring 8, 03046 Cottbus, Germany

2. Univ. Orléans, INSA-CVL, PRISME, EA 4229, F45072, Orléans, France

3. Thermo and Fluid Dynamics (FLOW), Vrije Universiteit Brussel, Belgium

4. LOGE Deutschland GmbH, Burger Chaussee 25, 03044 Cottbus, Germany

*Corresponding author: Lars Seidel, e-mail: Lars.Seidel@logesoft.com

Colloquium: Laminar flames

Word Count (Method 1):

\begin{tabular}{|l|l|}
\hline Abstract & 263 \\
\hline Main text & 3326 \\
\hline References & 682 \\
\hline Figure 1 & 227 \\
\hline Figure 2 & 178 \\
\hline Figure 3 & 223 \\
\hline Figure 4 & 138 \\
\hline Figure 5 & 182 \\
\hline Figure 6 & 305 \\
\hline Figure 7 & 180 \\
\hline Figure 8 & 133 \\
\hline Figure 9 & 356 \\
\hline Table 1 & 145 \\
\hline Total(excl. abstract) & 6075 \\
\hline
\end{tabular}

Color figures in the electronic version only.

Supporting information is available 


\section{Abstract}

Laminar flame speeds of ammonia with oxygen-enriched air (oxygen content varying from 2130 vol.\%) and ammonia-hydrogen-air mixtures (fuel hydrogen content varying from 0-30 vol.\%) at elevated pressure (1-10 bar) and temperature (298-473 K) were determined experimentally using a constant volume combustion chamber. Moreover, ammonia laminar flame speeds with helium as an inert were measured for the first time. Using these experimental data along with published ones, we have developed a newly compiled kinetic model for the prediction of the oxidation of ammonia and ammonia-hydrogen blends in freely propagating and burner stabilized premixed flames, as well as in shock tubes, rapid compression machines and a jet-stirred reactor. The reaction mechanism also considers the formation of nitrogen oxides, as well as the reduction of nitrogen oxides depending on the conditions of the surrounding gas phase. The experimental results from the present work and the literature are interpreted with the help of the kinetic model derived here. The experiments show that increasing the initial temperature, fuel hydrogen content, or oxidizer oxygen content causes the laminar flame speed to increase, while it decreases when increasing the initial pressure. The proposed kinetic model predicts the same trends than experiments and a good agreement is found with measurements for a wide range of conditions. The model suggests that under rich conditions the $\mathrm{N}_{2} \mathrm{H}_{2}$ formation path is favored compared to stoichiometric condition. The most important reactions under rich conditions are: $\mathrm{NH}_{2}+\mathrm{NH}=\mathrm{N}_{2} \mathrm{H}_{2}+\mathrm{H}, \mathrm{NH}_{2}+\mathrm{NH}_{2}=\mathrm{N}_{2} \mathrm{H}_{2}+\mathrm{H}_{2}, \mathrm{~N}_{2} \mathrm{H}_{2}+\mathrm{H}=\mathrm{NNH}+\mathrm{H}_{2}$ and $\mathrm{N}_{2} \mathrm{H}_{2}+\mathrm{M}=\mathrm{NNH}+\mathrm{H}+\mathrm{M}$. These reactions were also found to be among the most sensitive reactions for predicting the laminar flame speed for all the cases investigated.

Keywords: ammonia, laminar flame speed, kinetic modeling, ammonia-hydrogen, $\mathrm{NO}_{x}$ 


\section{Introduction}

Ammonia is a carbon free energy carrier. Its technical application is slightly hindered by the comparable low laminar flame speed. To consider ammonia $\left(\mathrm{NH}_{3}\right)$ as single or blend fuel, it is essential to have a deep understanding of the detailed chemical processes of fuel oxidation to $\mathrm{N}_{2}$ and $\mathrm{H}_{2} \mathrm{O}$ and further oxidation to emission formation, mainly $\mathrm{NO}$ and $\mathrm{NO}_{2}$. Moreover, the knowledge on $\mathrm{NH}_{3}$ kinetics is also needed to improve the general $\mathrm{NO}_{x}$ formation model. Ammonia is the smallest nitrogen containing fuel molecule. Several $\mathrm{NH}_{3}-\mathrm{NO}_{x}$ mechanisms have been developed in recent years, each with a different conditions of interest [1-3]. Shrestha et al. [4] published their $\mathrm{NH}_{3}$ model recently which covers a broad range of experimental conditions available from the literature, including $\mathrm{NO}_{x}$ formation and reduction in dependence on the surrounding environment. Mathieu et al. [1] established an ammonia oxidation mechanism, based on experiments in a shock tube (ST). They compared their work against nine different literature models to underline the large discrepancies between the ammonia mechanisms. Hayakawa et al. [5] measured laminar flame speeds of ammonia - air in a cylindrical combustion chamber under elevated pressure conditions. They compared their data against the prediction of five detailed mechanisms from the literature. Most mechanisms failed to predict laminar flame experiments. Xiao et al. [6] performed a comparative study on the performance of 12 different $\mathrm{NH}_{3}-\mathrm{NO}_{x}$ kinetic mechanisms to identify the best model. They used $\mathrm{NH}_{3} / \mathrm{H}_{2}$ laminar flame speed data from [7] and $\mathrm{NH}_{3}$ ignition delay time data from [1] to rate the model predictions. The majority of the kinetic models could not reproduce the experimental data for the investigated range of equivalence ratios. Recently, Pochet et al. [8] and He et al. [9] studied autoignition of neat $\mathrm{NH}_{3}$ and $\mathrm{NH}_{3} / \mathrm{H}_{2}$ blends in a rapid compression machine (RCM). Both studies assessed the performance of the various $\mathrm{NH}_{3}$ kinetic models including our previous work [4] against their experimental data and concluded that 
none of the mechanisms was able to reproduce the experiments satisfactorily. Han et al. [10] performed an experimental and kinetic modeling investigation on laminar flame speed for $\mathrm{NH}_{3} /$ air and different $\mathrm{NH}_{3} / \mathrm{H}_{2} / \mathrm{CO} / \mathrm{CH}_{4}$ air blends. The three investigated mechanisms from literature could not accurately predict the laminar burning velocity. Recently, Mei et al. [2] performed laminar flame speed experiments for oxygen enriched $\mathrm{NH}_{3} / \mathrm{O}_{2} / \mathrm{N}_{2}$ blends. They modified our previous work [4] to reach an agreement with their experiments. Their selection of the base model was founded on a previous comparative study, including work from different groups.

In general, the discrepancies between the kinetic model predictions are expected as the experimental database for ammonia oxidation is not yet broad enough. Uncertainties are found in the rate kinetic data as well as in the thermochemistry. Further experimental data are needed to allow further improvement of the kinetic models. The conclusion above includes that the further oxidation of intermediates to $\mathrm{NO}_{x}$ is not yet fully understood. Several researchers have already put their effort into the development of an $\mathrm{NH}_{3}-\mathrm{NO}_{x}$ kinetic model but still, a well-established and reliable model is not yet available. As discussed in [2] our recent model [4] was not validated for laminar flames but can be modified to include these experiments.

In this study, we present new experimental flame speed data together with a modification of our recent work to include these experiments in our validation database.

The aim of the present work is thus twofold:

1) to extend laminar flame speed data already published in [11], in the case of $\mathrm{NH} 3 / \mathrm{H} 2$ blend at higher pressure than atmospheric one, and also in the case of neat $\mathrm{NH} 3$ with enriched $\mathrm{O} 2$ conditions.Moreover, additional $\mathrm{NH}_{3}$ laminar flame speed measurement with $\mathrm{He}$ as an inert will be provided for the first time to investigate the influence of third body coefficients in pressure dependent reactions. 
2) to improve our previous model [4], based on the improved and broadened experimental database.

This work is an ongoing effort to develop a reliable and comprehensive mechanism for $\mathrm{NH}_{3}$ and $\mathrm{NH}_{3} / \mathrm{H}_{2}$ blends. Although the focus of this study is on laminar flame speed, the derived model is critically tested against the previous validation database; i.e. ignition delay times (IDT), speciation in jet-stirred reactors (JSR), and burner stabilized flames (BSF).

\section{Experimental set-up and processing}

The experiments were performed in the $4.2 \mathrm{~L}$ (inner diameter $200 \mathrm{~mm}$ ) spherical stainless steel combustion chamber, fully described in $[12,13]$. The fresh gases are heated up to a maximum initial temperature of $473 \mathrm{~K}$ by means of a heating wire. Before filling the sphere, a vacuum pump allows the evacuation of residual gases until a pressure $<0.009$ bar. Then all reactant gases are injected by a thermal flow meter. Before being introduced in the sphere, the inlet valve heats the mixture up to the required temperature with a maximum of $2 \mathrm{~K}$ uncertainty. To guarantee a perfectly homogeneous mixture, a fan runs during few seconds, but is stopped $10 \mathrm{~s}$ before the ignition to avoid any perturbation. The maximum deviation between the effective initial pressure inside the combustion chamber and the required initial pressure was estimated about $0.5 \%$. Two tungsten electrodes ( $1 \mathrm{~mm}$ diameter) with a conventional capacitive discharge ignition system are used, with an ignition coil time charge of $3 \mathrm{~ms}$ (i.e. discharge energy of less than $100 \mathrm{~mJ}$ ). The electrodes gap is adjusted to ensure a sufficient energy deposit to sustain the flame.

Experiments were carried out at various initial pressure, temperature, global equivalence ratio from 1-10 bar, 298-473 K and 0.8-1 respectively. The volume content of $\mathrm{H}_{2}$, $\mathrm{x}_{\mathrm{H}}$, was varied from 0 to $30 \%$ (in fuel). Synthetic air $\left(20.9 \% \mathrm{O}_{2} / 79.1 \% \mathrm{~N}_{2}\right)$ was used as ambient gas, but experiments were also performed for the neat ammonia cases with a variation of oxygen content, $\mathrm{x}_{\mathrm{O} 2}(23,25,27$ and 
$30 \%$ vol, in oxidizer). Last, a set of experiments was also conducted by using He as inert gases for 27 and $30 \%$ vol. $\mathrm{O}_{2}$ cases. For each condition, at least 3 tests were carried out in order to obtain average and standard deviation values, represented by error bars in the following figures.

To measure laminar flame speeds, the Schlieren technique was implemented thanks to two opposite and transparent windows (diameter $70 \mathrm{~mm}$ ). The Schlieren pathway is made by using a continuous LED, coupled with a $0.8 \mathrm{~mm}$ pinhole and 2 convex mirrors ( $864 \mathrm{~mm}$ focal length). At the focus point of the second mirror, a $0.5 \mathrm{~mm}$ dot is placed with two lenses $(250 \mathrm{~mm}$ and 400 $\mathrm{mm}$ ) to focus the Schlieren images on the Phantom v1210 high-speed CMOS ship. Images of 640 x 800 pixels $^{2}$ were recorded with a magnification ratio of $0.11 \mathrm{~mm} /$ pixel. The frame rate was adapted from 5 to $8 \mathrm{kHz}$. The temporal evolution of the expanding spherical flame was then processed to get the flame front radius, $r_{f}$. The laminar flame propagation speed, $V_{s}$ was calculated from the time derivative of $r_{f}$. The non-linear methodology as suggested by Kelley and Law [14] and Halter et al. [15] was used to estimate the unstretched laminar flame velocity $V_{s}^{0}$, as $\left(\frac{V_{s}}{V_{s}^{0}}\right)^{2} \ln \left(\frac{V_{s}}{V_{s}^{0}}\right)^{2}=-2 \frac{L_{b} K}{V_{s}^{0}}$, with $K$ the stretch rate impacting the flame, estimated by $K=\frac{2}{r_{f}} \frac{d r_{f}}{d t}$ and $L_{b}$ the Markstein length for burned gases.

This methodology was applied for flame diameter greater than $6.5 \mathrm{~mm}$ to avoid any ignition effect and lower than $25 \mathrm{~mm}$ corresponding to a burned gas volume less than $1 \%$ of sphere volume, to consider constant pressure chamber and avoid confinement effect.

Then the fundamental unstretched laminar burning velocity $S_{L}{ }^{0}$ is obtained with the expansion factor, $\rho_{b} / \rho_{u}$ as $S_{L}^{0}=\frac{\rho_{b}}{\rho_{u}} V_{s}^{0}$, with $\rho_{b}$ and $\rho_{u}$ the burned and the unburned gases densities respectively. 
For low unstretched laminar burning velocity $\left(<20 \mathrm{~cm} \cdot \mathrm{s}^{-1}\right)$, radiative heat loss induced error can be of importance. Those effects were already addressed in [11]. In the present work, using the correlation of $\mathrm{Yu}$ et al.[16], the worst case is obtained at $473 \mathrm{~K}, 3$ bar where an underprediction of about $12 \%$ is calculated for neat ammonia corresponding to an absolute error of $1 \mathrm{~cm} / \mathrm{s}$. The error decreases down to $1 \%$ for the fastest flames.

\section{Kinetic modeling}

The kinetic model used in this work follows our previous publication [4] and was revised to predict the new experimental data determined in this work and in our recent work [11] for the wide range of conditions. In this work, the reaction rate parameter of several reactions were updated based on the literature study. The changes were made in the $\mathrm{NH}_{3}, \mathrm{NH}_{2}, \mathrm{NH}, \mathrm{N}_{2} \mathrm{H}_{2}$, and $\mathrm{H}_{2} \mathrm{NO}$ submechanisms and modified reactions are listed in Table 1. The model developed in this work is validated against 104 sets (approximately 500 data points) of laminar flame speed data (covering $\phi=0.7-1.7, \mathrm{~T}=298-473 \mathrm{~K}, \mathrm{P}=1-10 \mathrm{bar})$. The complete kinetic scheme is provided as supporting information (SI).

Table 1: List of reactions with updated rate parameter in the detailed model, found in the SI.

\begin{tabular}{ll}
\hline Reactions & Source of adopted rate \\
\hline $\mathrm{NH}_{2}+\mathrm{H}(+\mathrm{M})=\mathrm{NH}_{3}(+\mathrm{M})$ & Altinay and Macdonald [17] \\
$\mathrm{NH}_{3}+\mathrm{H}=\mathrm{NH}_{2}+\mathrm{H}_{2}$ & Nguyen and Stanton [18] \\
$\mathrm{NH}_{2}+\mathrm{H}=\mathrm{NH}+\mathrm{H}_{2}$ & Samu et al. [19] \\
$\mathrm{NH}_{2}+\mathrm{O}=\mathrm{HNO}+\mathrm{H}$ & Miller et al. [20] /2 \\
$\mathrm{NH}_{2}+\mathrm{HO}_{2}=\mathrm{NH}_{3}+\mathrm{O}_{2}$ & Sumathi et al. [21] \\
$\mathrm{NH}_{2}+\mathrm{HO}_{2}=\mathrm{H}_{2} \mathrm{NO}+\mathrm{OH}$ & Sumathi et al. [21] \\
$\mathrm{NH}_{2}+\mathrm{HO}_{2}=\mathrm{HNO}+\mathrm{H}_{2} \mathrm{O}$ & Sumathi et al. [21] \\
$\mathrm{NH}_{2}+\mathrm{HO}_{2}=\mathrm{HON}+\mathrm{H}_{2} \mathrm{O}$ & Sumathi et al. [21] \\
$\mathrm{N}_{2} \mathrm{H}_{2}+\mathrm{M}=\mathrm{NNH}+\mathrm{H}+\mathrm{M}$ & Mei et al. [2] x 0.75 \\
$\mathrm{N}_{2} \mathrm{H}_{2}+\mathrm{H}=\mathrm{NNH}+\mathrm{H}_{2}$ & Zheng et al. [22] x 2 \\
$\mathrm{NH}_{2}+\mathrm{NH}=\mathrm{N}_{2} \mathrm{H} 2+\mathrm{H}$ & Klippenstein et al. [23] x 2 \\
$\mathrm{NH}_{2}+\mathrm{NH} 2=\mathrm{N} 2 \mathrm{H} 2+\mathrm{H}_{2}$ & Klippenstein et al. [23] x 2
\end{tabular}




\begin{tabular}{ll}
$\mathrm{NH}+\mathrm{OH}=\mathrm{HNO}+\mathrm{H}$ & Klippenstein et al. [23] \\
$\mathrm{NH}+\mathrm{OH}=\mathrm{N}+\mathrm{H}_{2} \mathrm{O}$ & Klippenstein et al. [23] \\
$\mathrm{H}_{2} \mathrm{NO}+\mathrm{O}_{2}=\mathrm{HNO}+\mathrm{HO}_{2}$ & Song et al. [3] x 0.78 \\
\hline
\end{tabular}

\section{Results and discussion}

The symbols in figures are experimental data from this work or from the literature, lines are model prediction. All the simulations are performed with the LOGEresearch v1.10 [24] software suit. The model from this work is validated against 104 data sets of laminar flame speed measurements from different sources (32 data are from this work and 40 data (for $\mathrm{NH}_{3} / \mathrm{H}_{2}$ ) are from our recent work [11] and others are from published literature [2,5,7,10,25-32]).

\subsection{Laminar flame speed of $\mathrm{NH}_{3}$ and $\mathrm{NH}_{3} / \mathrm{H}_{2}$}

Figure 1a displays the laminar flame speeds of $\mathrm{NH}_{3} /$ air at $1 \mathrm{~atm}$ and $298 \mathrm{~K}$ as a function of equivalence ratio $(\phi)$. Literature data, own measurements and calculations are shown. Good agreement can be observed among the measured laminar flame speeds for fuel-lean and stoichiometric conditions while discrepancies can be observed on the fuel-rich side. The model (from this work) captures the experimental trends from lean to stoichiometric conditions very well. For lean and stoichiometric conditions, the model agrees with most measurements. For fuel-rich conditions, the best agreement is found with the older measurements from Ronney 1988 [30] and with the very recent experiments from Mei et al. 2019 [2]. Furthermore, particularly for fuel-rich conditions the model in this work shows an improved agreement against the measurements, compared to the model from our previous work [4]. This improvement is mainly due to the update in the rate parameters for the reactions involving $\mathrm{N}_{2} \mathrm{H}_{2}$ (listed in Table 1). Reaction flow analysis (see Fig. 2, only major paths are shown here) reveals that reaction paths involving $\mathrm{N}_{2} \mathrm{H}_{2}$ are favored more at rich conditions. As can be seen in Fig. 2 at rich environment ( $\phi=1.4-$ red numbers) most 
of the $\mathrm{NH}_{2}$ reacts to $\mathrm{N}_{2} \mathrm{H}_{2}$ reacting with $\mathrm{NH}$ or self-recombining. This route increases its flux by $60 \%$ when compared to stoichiometric conditions. This increased importance of $\mathrm{N}_{2} \mathrm{H}_{2}$ formation via the $\mathrm{NH}_{2}$ route is compensated by the shrink in the $\mathrm{NH}$ formation route.

Figure $1 \mathrm{~b}$ shows the laminar flame speed of $\mathrm{NH}_{3} / \mathrm{H}_{2} /$ air blends at stoichiometric and standard condition (1 atm, $298 \mathrm{~K})$ at varying $\mathrm{H}_{2}$ content (0-100\%) in the fuel blend. Most measurements limit the hydrogen content to $60 \%$. The measurement from Kumar 2013 [31] at $60 \% \mathrm{H}_{2}$ and above diverge from other experimental measurements. It can be observed that the updated model from this work (solid line) accurately predicts the laminar flame speed. Calculations with our mechanism from prior work [4] is also shown (dashed line). It is found that for $\mathrm{NH}_{3} / \mathrm{H}_{2} /$ air blends the reactions $\mathrm{NNH}+\mathrm{O}_{2}=\mathrm{N}_{2}+\mathrm{HO}_{2}, \mathrm{NH}_{2}+\mathrm{O}=\mathrm{HNO}+\mathrm{H}$ and $\mathrm{NH}+\mathrm{OH}=\mathrm{HNO}+\mathrm{H}$ are important for predicting laminar flame speed, with increasing importance with increasing $\mathrm{H}_{2}$ content in the blend.

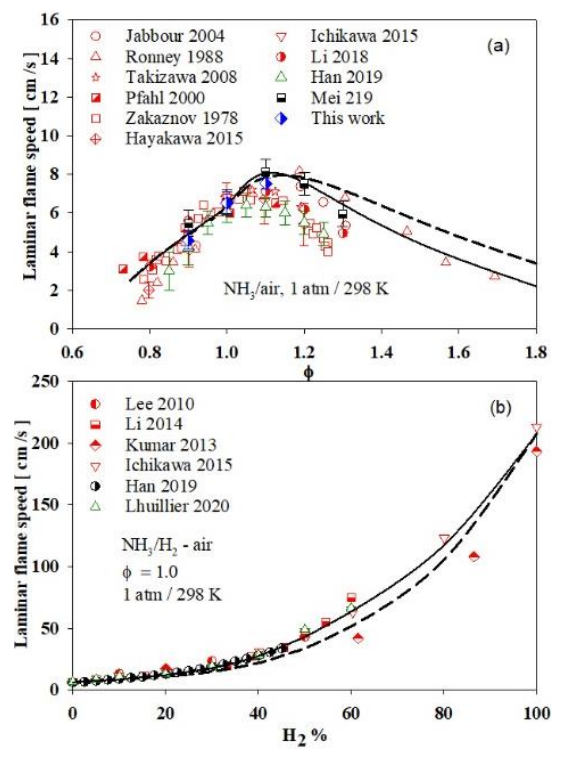

Figure 1: Laminar flame speed at 1 atm and $298 \mathrm{~K}$ for $\mathrm{NH}_{3} /$ air (a) and for stoichiometric conditions for $\mathrm{NH}_{3} / \mathrm{H}_{2} /$ air (b). Symbols: measurements published literature [2,5,10,26-30,32,33]. Dashed lines: previous model [4], solid lines: this work. 


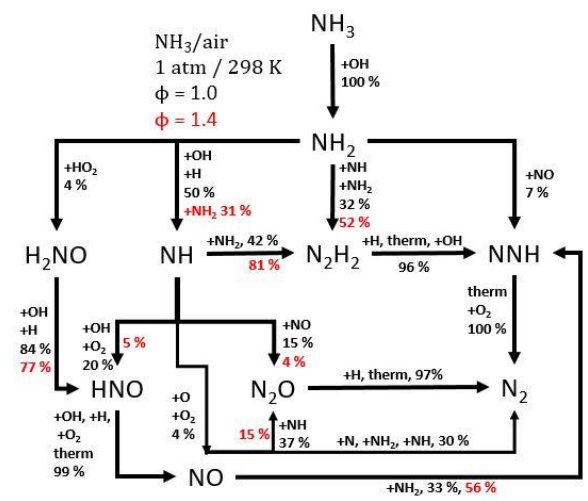

Figure 2: Integrated $\mathrm{N}$-atom mass flux analysis at $1 \mathrm{~atm}$ and $298 \mathrm{~K}$ for $\phi=1.0$ and $\phi=1.4 \mathrm{NH}_{3} /$ air blends. Numbers are the percentage of the reactant forming the respective product. Major changes in flow highlighted by red for $\phi=1.4$.

Figure 3 shows the new measured laminar flames speeds (symbols) compared against the model predictions using our previous work [4] and the model improvements from this work for $\mathrm{NH}_{3} / \mathrm{H}_{2} /$ air at $473 \mathrm{~K}$ and 1 [11] and 3 bar. Simulations were performed using a detailed multicomponent diffusion model to consider the strong thermo diffusion of the $\mathrm{H}$ and $\mathrm{H}_{2}$. It can be seen that as the hydrogen content in the mixture is increased laminar flame speed is also increased. The experiments show peak laminar flame speed at $\phi=1.1$, which is well predicted by the models. It can be observed that below $10 \% \mathrm{H}_{2}$ the laminar flame speed does not increase significantly, but does for $\mathrm{H}_{2}$ contents in the blend above $10 \%$ (see Fig. 1b). For 1 bar (Fig. 3a) at $\phi=1.1$ with $10 \%$ and $30 \% \mathrm{H}_{2}$, laminar flame speed is increased by factor 1.4 and 2.8 respectively and for 3 bar (Fig. 3b) at same condition laminar flame speed is increased by factor 1.3 and 2.0 respectively compared to neat ammonia flame. This leads to the conclusion that the impact of $\mathrm{H}_{2}$ on the laminar flame speed of $\mathrm{NH}_{3}$ /air is reduced with increasing pressure. Figure 3 also demonstrates that the model predictions from this work agree well with the most of the 
measurements while slightly underpredicting for $30 \% \mathrm{H}_{2}$ (Fig. 3a) at lean to stoichiometric conditions.

Figure 4 shows new data the laminar flame speeds of $\mathrm{NH}_{3} / \mathrm{H}_{2} /$ air at $\phi=1.1,473 \mathrm{~K}$, and pressure of 5, 7 and 10 bar respectively as a function of $\mathrm{H}_{2}$ content in the fuel blend. It can be observed that the model predicts slightly higher flame speed compared to measurements but remain within the error margins of experiments. There are limited number of experimental data in literature at higher pressure (we believe this study is first to report data at 7 and 10 bar).

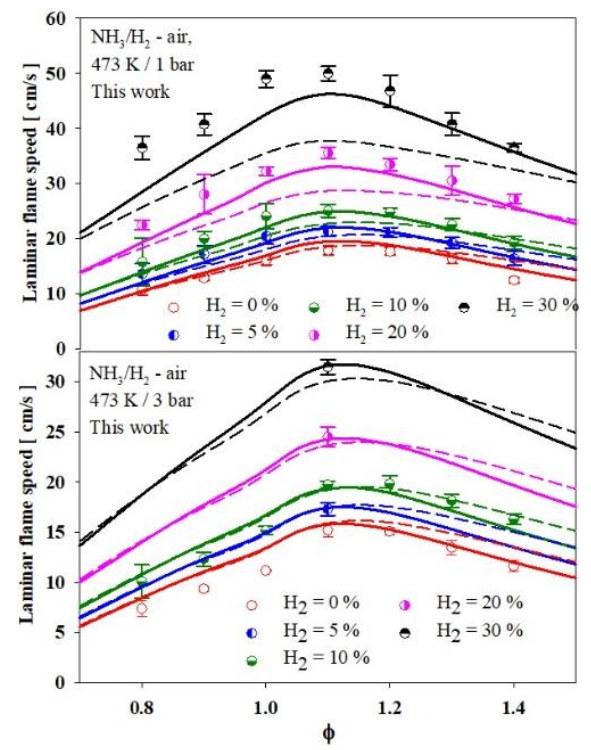

Figure 3: Laminar flame speeds of $\mathrm{NH}_{3} / \mathrm{H}_{2} /$ air at $473 \mathrm{~K}$ and 1 bar (a) and 3 bar (b) at varying $\mathrm{H}_{2}$ content. Symbols: measurements from this work and [11]. Dashed lines: previous model [4], solid lines: this work. 


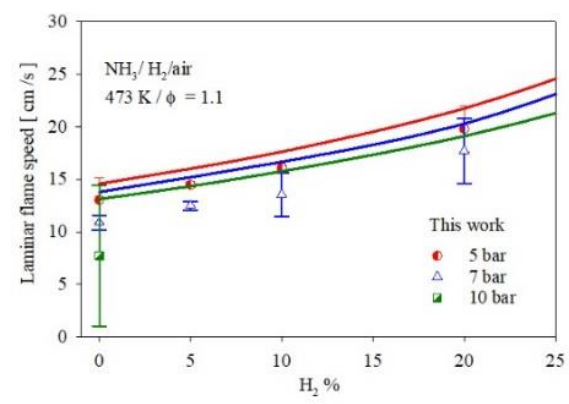

Figure 4: Laminar flame speed of $\mathrm{NH}_{3} / \mathrm{H}_{2} /$ air at $473 \mathrm{~K}$ and varying $\mathrm{H}_{2}$ content at $\phi=1.1$ and 510 bar. Symbols: experiments this work. Lines: simulations this work.

To outline important reactions with regard to $\mathrm{NH}_{3} / \mathrm{H}_{2} /$ air laminar flame speeds a reaction sensitivity analysis is conducted which is presented in Fig. 5 for $\phi=1.0$ at 1 bar and $473 \mathrm{~K}$ and different $\mathrm{H}_{2}$ contents $(0-30 \%)$ in the fuel blend. In Fig. 5 positive sensitivity means reaction promotes the reactivity (increased flame speed) and negative sensitivity means reaction retards the reactivity. The chain branching reaction from the hydrogen chemistry $\left(\mathrm{O}_{2}+\mathrm{H}=\mathrm{OH}+\mathrm{O}\right)$ is also for Ammonia the most sensitive reaction under all conditions. Its sensitivity increases as the $\mathrm{H}_{2}$ content is increased and explains the accelerating laminar flame speed with increasing $\mathrm{H}_{2}$ content. Other most sensitive reactions involve the NNH radical, which is a key radical in the ammonia oxidation chemistry. The thermal dissociation $\mathrm{NNH}=\mathrm{N}_{2}+\mathrm{H}$ competes with the oxidation $\mathrm{NNH}+\mathrm{O}_{2}=\mathrm{N}_{2}+\mathrm{HO}_{2}$. The former reaction promotes the reactivity by producing more reactive $\mathrm{H}$ atoms while the latter retards the system reactivity by producing less reactive $\mathrm{HO}_{2}$ radicals. Sensitivity increases with increasing $\mathrm{H}_{2}$ content in the blend for both reactions. The reactions, $\mathrm{NH}_{2}+\mathrm{NO}=\mathrm{NNH}+\mathrm{OH}$ and $\mathrm{N}_{2} \mathrm{H}_{2}+\mathrm{M}=\mathrm{NNH}+\mathrm{H}+\mathrm{M}$ are chain branching reactions promoting the reactivity of the system. With respect to the increasing $\mathrm{H}_{2}$ content, the sensitivity of the former reaction increases while sensitivity of later reaction decreases. A further important reaction is $\mathrm{NH}_{2}+\mathrm{NH}=\mathrm{N}_{2} \mathrm{H}_{2}+\mathrm{H}$, with the highest contribution to the formation of $\mathrm{N}_{2} \mathrm{H}_{2}$ and consuming the 
important key radicals $\left(\mathrm{NH}_{2}\right.$ and $\left.\mathrm{NH}\right)$. The sensitivity of this reaction also increases with increase in $\mathrm{H}_{2}$ content. Similar observations can be drawn for other reactions as well. Additional model validation of $\mathrm{NH}_{3}$ /air and $\mathrm{NH}_{3} / \mathrm{H}_{2} /$ air laminar flame speeds for wide range of experimental condition is shown in SI (see Fig. S1 - S8).

Furthermore, for comparison study simulation has also been performed using three different mechanisms from literature (Glarborg et al. [34], Otomo et al. [35] and Stagni et al. [36]). The performance of these mechanism against the experimental data (shown in Fig. 1, Fig. 3 and Fig. 4) are provided in SI (Fig. S12-S15). Among these, model from Glarborg [34] overpredicts the laminar flame speed at all condition, Otomo model [35] underpredicts mainly for $\mathrm{NH}_{3} / \mathrm{H}_{2}$ blends, and Stagni model [36] performance is similar as our mechanism from this work.

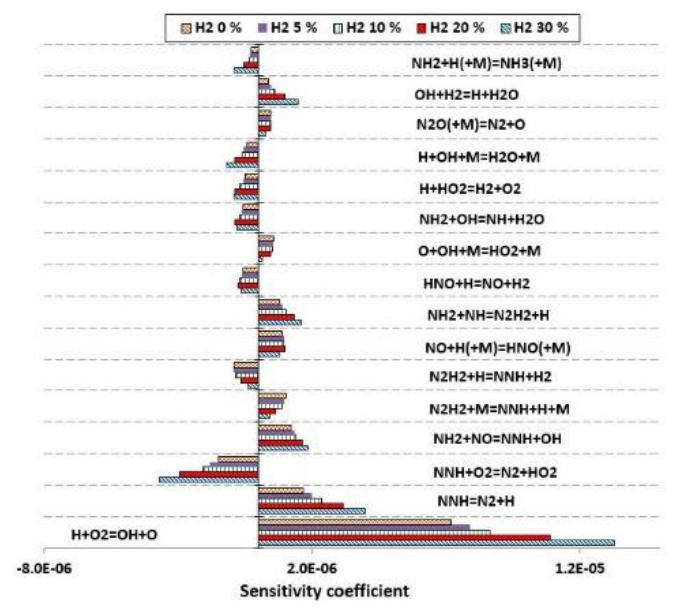

Figure 5: Reaction sensitivity analysis for laminar flame speed of $\mathrm{NH}_{3} / \mathrm{H}_{2} /$ air at $\phi=1.0,1$ bar and $473 \mathrm{~K}$ with varying $\mathrm{H}_{2}$ content in the fuel blend.

\subsection{Laminar flame speed of $\mathrm{NH}_{3}$ with an enriched oxygen content}


Figure 6 shows laminar flame-speed comparisons between model predictions and new measurements for $\mathrm{NH}_{3} / \mathrm{O}_{2} / \mathrm{N}_{2}$ with varying $\mathrm{O}_{2}$ content (21-30\%) at $298 \mathrm{~K}(\mathrm{a}), 323 \mathrm{~K}(\mathrm{~b})$ and 373 $\mathrm{K}$ (c) as a function of $\phi$. The experiments show that increasing the $\mathrm{O}_{2}$ content increases the laminar flame speed and the same trend is predicted by the model. The sensitivity on $\mathrm{O}_{2}$ is slightly overpredicted, which is seen under lean conditions. The model follows the experimental trend very well for all the conditions. For completeness it is also stated that the agreement is better for 298 and $373 \mathrm{~K}$ than at $323 \mathrm{~K}$. The laminar flame speed depends almost linearly on the $\mathrm{O}_{2}$ content in the oxidizer (see also Fig. S17 in SI). The influence of $\mathrm{O}_{2}$ is mainly explained by the increased adiabatic flame temperature. The influence of the chemistry is discussed in Fig. 7. It should be noted that with increasing $\mathrm{H}_{2}$ in fuel blend the growth is exponential while this does not hold true for $\mathrm{O}_{2}$ (see Fig. 2b and Fig. S17).

To explore the important reactions for predicting the laminar flame speeds at varying $\mathrm{O}_{2}$ content, reaction sensitivity analysis is performed. Figure 7 displays the 15 highest sensitive reactions at $\phi=1.0,1$ bar and $298 \mathrm{~K}$. The highest sensitivity of the branching reaction $\mathrm{O}_{2}+\mathrm{H}=\mathrm{OH}+\mathrm{O}$ is expected. Its sensitivity increases with increasing $\mathrm{O}_{2}$ content in the oxidizer. Most of the sensitive reactions are unchanged when compared to Fig. $5\left(\mathrm{H}_{2}\right.$ addition to the fuel). Reaction $\mathrm{NNH}=\mathrm{N}_{2}+\mathrm{H}$ and $\mathrm{NNH}+\mathrm{O}_{2}=\mathrm{N}_{2}+\mathrm{HO}_{2}$ which showed an increased sensitivity trend with an increase in $\mathrm{H}_{2}$ content in the $\mathrm{NH}_{3} / \mathrm{H}_{2} /$ air blend (Fig. 5), shows a decreasing sensitivity trend with an increase in $\mathrm{O}_{2}$ content. Similarly, reaction $\mathrm{N}_{2} \mathrm{H}_{2}+\mathrm{M}=\mathrm{NNH}+\mathrm{H}+\mathrm{M}$ and $\mathrm{N}_{2} \mathrm{H}_{2}+\mathrm{H}=\mathrm{NNH}+\mathrm{H}_{2}$ show an increasing trend in sensitivity contrary to Fig. 5. However, other important reactions $\mathrm{NH}_{2}+\mathrm{NO}=\mathrm{NNH}+\mathrm{OH}$ and $\mathrm{NH}_{2}+\mathrm{NH}=\mathrm{N}_{2} \mathrm{H}_{2}+\mathrm{H}$ show a similar trend decreasing and increasing. Hence the chemical effect of $\mathrm{O}_{2}$ enrichment is more complex. It is, however governed by the chain branching reaction $\mathrm{O}_{2}+\mathrm{H}=\mathrm{OH}+\mathrm{O}$. 
The prediction of different models from literature [34-36] was compared against the present experimental data (see SI Fig. S22 - Fig. S24). The model from Glarborg [34] overpredicts the laminar flame speed at all conditions, the Otomo model [35] underpredicts mainly at rich side, and Stagni model [36] performance is similar as our model from this work.

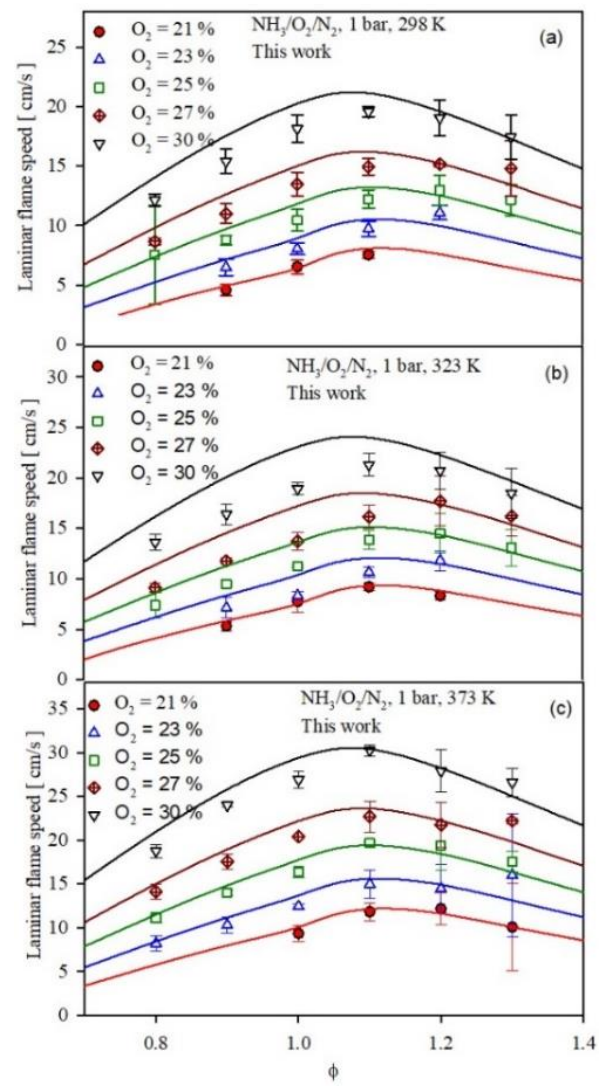

Figure 6: Laminar flame speed of $\mathrm{NH}_{3} / \mathrm{O}_{2} / \mathrm{N}_{2}$ at 1 bar and different temperatures with varying $\mathrm{O}_{2}$ content $(21-30 \%)$. At $298 \mathrm{~K}$ (a), $323 \mathrm{~K}$ (b) and $373 \mathrm{~K}$ (c). Symbols: measurements from this work. Lines: model prediction from this work. 


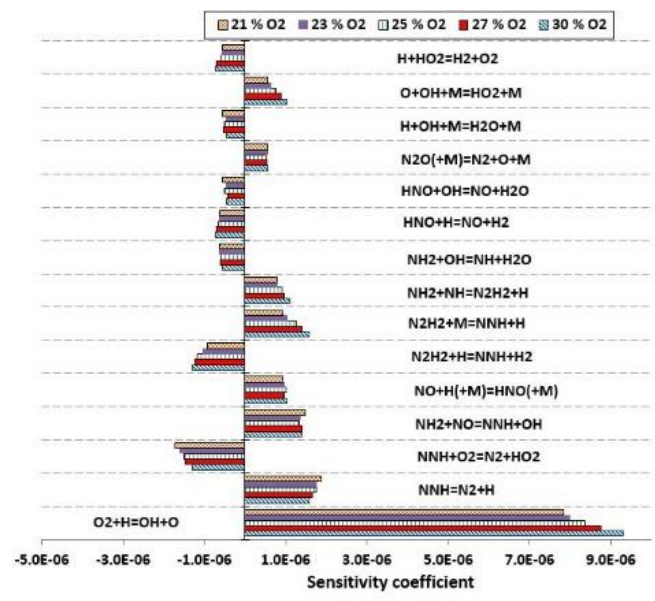

Figure 7: Reaction sensitivity analysis for laminar flame speed of $\mathrm{NH}_{3} / \mathrm{O}_{2} / \mathrm{N}_{2}$ at $\phi=1.0,1$ bar and $298 \mathrm{~K}$ with varying $\mathrm{O}_{2}$ content $(21-30 \%)$.

Figure 8 shows the laminar flame speeds of $\mathrm{NH}_{3} / \mathrm{O}_{2} / \mathrm{He}$ blend compared to the model prediction for 27 and $30 \% \mathrm{O}_{2}$ at $373 \mathrm{~K}$ and model predictions for $21 \% \mathrm{O}_{2}$. This experiment varies the heat capacity on the one hand, and the collision efficiency on the other hand of the inert gas in the oxidizer. The strong increase in laminar flame speed compared to experiments with $\mathrm{N}_{2} / \mathrm{O}_{2}$ oxidizer blends is mainly explained by the increased adiabatic flame temperature. The model predicts slightly higher laminar flame speed at lean and stoichiometric conditions and shows much better agreement on the rich side.

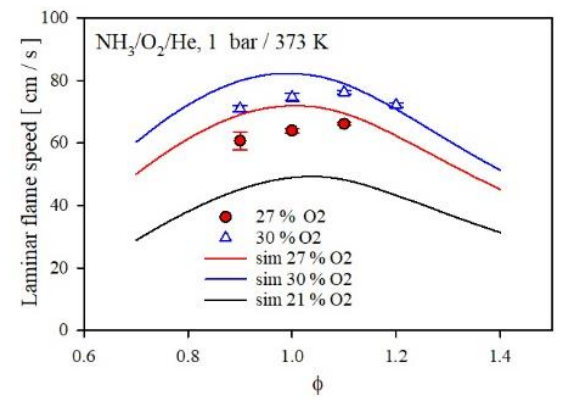

Figure 8: Laminar flame speed of $\mathrm{NH}_{3} / \mathrm{O}_{2} / \mathrm{He}$ at 1 bar and $373 \mathrm{~K}$ and different $\mathrm{O}_{2}$ content. Symbols: this work. Lines: this work. 


\subsection{Model validation against literature data for IDT, speciation in BSF and JSR}

Finally, we demonstrate for completeness of this paper that the modified model still predicts the validation experiments from previous work. Figure 9a shows the comparison between the model predictions against selected experimental data for ignition delay times in shock tube [1] and RCM [9] for $\mathrm{NH}_{3} / \mathrm{O}_{2} / \mathrm{Ar}$ blend. The model predictions are in good agreement with the experimental data for a wide range of pressure over the whole temperature range investigated. Figure 9 (b: speciation in $\mathrm{NH}_{3} / \mathrm{NO} / \mathrm{Ar}$, BSF (295K, 7.2kPa), (c, d): speciation during $\mathrm{H}_{2} / \mathrm{O}_{2} / \mathrm{N}_{2}$ oxidation in JSR doped with $220 \mathrm{ppm}$ of NO) compares the model prediction against the experimental data from the literature and good agreement is found. Additional model validation for IDT, BSF, and JSR is shown in SI to offer a broad data base (Fig. S25 - S31).

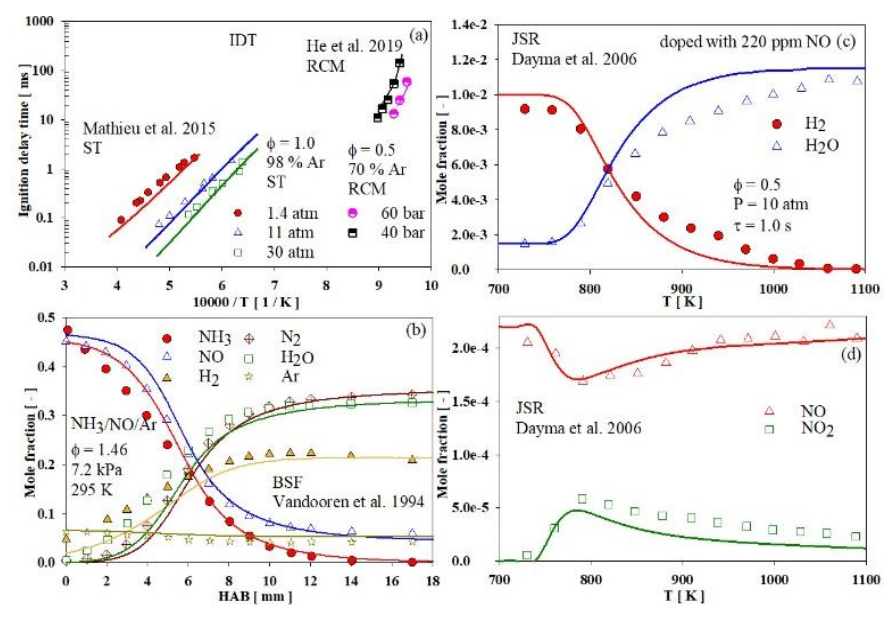

Figure 9: Comparison between model prediction and experimental data from literature for $\mathrm{NH}_{3} / \mathrm{O}_{2} / \mathrm{Ar}$, IDT (in ST and RCM) (a); for $\mathrm{NH}_{3} / \mathrm{NO} / \mathrm{Ar}\left(\phi=1.46\right.$ ), BSF (b); and for $\mathrm{H}_{2} / \mathrm{O}_{2} / \mathrm{NO}$ $(220 \mathrm{ppm}) / \mathrm{N}_{2}(\phi=0.5,10 \mathrm{~atm}, \tau=1.0 \mathrm{~s})$, JSR (c, d). Symbols: measurements [1,37,38], lines: this work. 


\section{Conclusion}

New data of the laminar flame speed of $\mathrm{NH}_{3}$ enriched with $\mathrm{O}_{2}$ and $\mathrm{NH}_{3} / \mathrm{H}_{2}$ blends have been studied experimentally at 1-10 bar, 298-473 K using a constant pressure combustion vessel. Based on the present measurements and published experimental data, a reaction mechanism for the oxidation of $\mathrm{NH}_{3}$ and $\mathrm{NH}_{3} / \mathrm{H}_{2}$ blends is developed. A number of published experiments have been selected to demonstrate that important features of the ammonia chemistry are well captured by the mechanism that was modified to include laminar flame speed prediction. Overall, there is a good agreement between model predictions and experimental measurements for the wide range of experimental conditions investigated. It is found that laminar flame speed of neat ammonia can be increased by increasing the oxygen content or using hydrogen as fuel blend. To rate the sensitivity of $\mathrm{H}_{2}$ addition to the fuel blend or $\mathrm{O}_{2}$ enrichment in the oxidizer we compare the data from Fig. $1 \mathrm{~b}$ and Fig. 6 a at $1 \mathrm{~atm}, 298 \mathrm{~K}$ and $\phi=1.0$. For $30 \% \mathrm{O}_{2}$ (in oxidizer stream) the laminar flame speed of $\mathrm{NH}_{3}$ is increased by factor 2.8 while $30 \% \mathrm{H}_{2}$ (in fuel stream) increases flame speed by factor 2.9. Hence, $9 \%$ increase of $\mathrm{O}_{2}$ (compared to air) content has the same effect as $30 \% \mathrm{H}_{2}$ in the fuel blend.

\section{Acknowledgements}

The research leading to these results has received funding from the French Government's “Investissement d'Avenir” program: “Laboratoire d'Excellence CAPRYSSES” (Grant No ANR11- LABX-0006-01).

\section{References}

[1] O. Mathieu, E.L. Petersen, Experimental and modeling study on the high-temperature 
oxidation of Ammonia and related NOx chemistry, Combust. Flame. 162 (2015) 554-570. doi:10.1016/j.combustflame.2014.08.022.

[2] B. Mei, X. Zhang, S. Ma, M. Cui, H. Guo, Z. Cao, Y. Li, Experimental and kinetic modeling investigation on the laminar flame propagation of ammonia under oxygen enrichment and elevated pressure conditions, Combust. Flame. 210 (2019) 236-246. doi:10.1016/j.combustflame.2019.08.033.

[3] Y. Song, H. Hashemi, J.M. Christensen, C. Zou, P. Marshall, P. Glarborg, Ammonia oxidation at high pressure and intermediate temperatures, Fuel. 181 (2016) 358-365. doi:10.1016/J.FUEL.2016.04.100.

[4] K.P. Shrestha, L. Seidel, T. Zeuch, F. Mauss, Detailed Kinetic Mechanism for the Oxidation of Ammonia Including the Formation and Reduction of Nitrogen Oxides, Energy \& Fuels. (2018). doi:10.1021/acs.energyfuels.8b01056.

[5] A. Hayakawa, T. Goto, R. Mimoto, Y. Arakawa, T. Kudo, H. Kobayashi, Laminar burning velocity and Markstein length of ammonia/air premixed flames at various pressures, Fuel. 159 (2015) 98-106. doi:10.1016/j.fuel.2015.06.070.

[6] H. Xiao, A. Valera-Medina, Chemical Kinetic Mechanism Study on Premixed Combustion of Ammonia/Hydrogen Fuels for Gas Turbine Use, J. Eng. Gas Turbines Power. 139 (2017) 081504. doi:10.1115/1.4035911.

[7] J. Li, H. Huang, N. Kobayashi, Z. He, Y. Nagai, Study on using hydrogen and ammonia as fuels: Combustion characteristics and NOx formation, Int. J. Energy Res. 38 (2014) 12141223. doi:10.1002/er.3141. 
[8] M. Pochet, V. Dias, B. Moreau, F. Foucher, H. Jeanmart, F. Contino, Experimental and numerical study, under LTC conditions, of ammonia ignition delay with and without hydrogen addition, Proc. Combust. Inst. 37 (2019) 621-629. doi:10.1016/J.PROCI.2018.05.138.

[9] X. He, B. Shu, D. Nascimento, K. Moshammer, M. Costa, R.X. Fernandes, Auto-ignition kinetics of ammonia and ammonia/hydrogen mixtures at intermediate temperatures and high pressures, Combust. Flame. 206 (2019) 189-200.

doi:10.1016/j.combustflame.2019.04.050.

[10] X. Han, Z. Wang, M. Costa, Z. Sun, Y. He, K. Cen, Experimental and kinetic modeling study of laminar burning velocities of NH3/air, NH3/H2/air, NH3/CO/air and NH3/CH4/air premixed flames, Combust. Flame. 206 (2019) 214-226. doi:10.1016/j.combustflame.2019.05.003.

[11] C. Lhuillier, P. Brequigny, N. Lamoureux, F. Contino, C. Mounaïm-Rousselle, Experimental investigation on laminar burning velocities of ammonia/hydrogen/air mixtures at elevated temperatures, Fuel. (2019) 116653. doi:10.1016/J.FUEL.2019.116653.

[12] P. Brequigny, G. Dayma, F. Halter, C. Mouna??m-Rousselle, T. Dubois, P. Dagaut, Laminar burning velocities of premixed nitromethane/air flames: An experimental and kinetic modeling study, Proc. Combust. Inst. 35 (2015) 703-710. doi:10.1016/j.proci.2014.06.126.

[13] B. Galmiche, F. Halter, F. Foucher, Effects of high pressure, high temperature and dilution on laminar burning velocities and Markstein lengths of iso-octane/air mixtures, Combust. 
Flame. 159 (2012) 3286-3299. doi:10.1016/j.combustflame.2012.06.008.

[14] A.P. Kelley, C.K. Law, Nonlinear effects in the extraction of laminar flame speeds from expanding spherical flames, Combust. Flame. 156 (2009) 1844-1851. doi:10.1016/j.combustflame.2009.04.004.

[15] F. Halter, T. Tahtouh, C. Mounaïm-Rousselle, Nonlinear effects of stretch on the flame front propagation, Combust. Flame. 157 (2010) 1825-1832. doi:10.1016/j.combustflame.2010.05.013.

[16] H. Yu, W. Han, J. Santner, X. Gou, C.H. Sohn, Y. Ju, Z. Chen, Radiation-induced uncertainty in laminar flame speed measured from propagating spherical flames, Combust. Flame. 161 (2014) 2815-2824. doi:10.1016/j.combustflame.2014.05.012.

[17] G. Altinay, R.G. Macdonald, Determination of the Rate Constants for the NH2(X2B1) + $\mathrm{NH} 2(\mathrm{X} 2 \mathrm{~B} 1)$ and $\mathrm{NH} 2(\mathrm{X} 2 \mathrm{~B} 1)+\mathrm{H}$ Recombination Reactions in N2 as a Function of Temperature and Pressure, J. Phys. Chem. A. 119 (2015) 7593-7610. doi:10.1021/acs.jpca.5b00917.

[18] T.L. Nguyen, J.F. Stanton, Ab initio thermal rate coefficients for $\mathrm{H}+\mathrm{NH} 3 \rightleftharpoons \mathrm{H} 2+\mathrm{NH}$ 2, Int. J. Chem. Kinet. 51 (2019) 321-328. doi:10.1002/kin.21255.

[19] V. Samu, T. Varga, I. Rahinov, S. Cheskis, T. Turányi, Determination of rate parameters based on $\mathrm{NH} 2$ concentration profiles measured in ammonia-doped methane-air flames, Fuel. 212 (2018) 679-683. doi:10.1016/J.FUEL.2017.10.019.

[20] J.A. Miller, M.D. Smooke, R.M. Green, R.J. Kee, Kinetic Modeling of the Oxidation of Ammonia in Flames, Combust. Sci. Technol. 34 (1983) 149-176. 
doi:10.1080/00102208308923691.

[21] R. Sumathi, S.D. Peyerimhoff, A quantum statistical analysis of the rate constant for the HO2 + NH2 reaction, Chem. Phys. Lett. 263 (1996) 742-748. doi:10.1016/S00092614(96)01283-3.

[22] J. Zheng, R.J. Rocha, M. Pelegrini, L.F.A. Ferrão, E.F.V. Carvalho, O. Roberto-Neto, F.B.C. MacHado, D.G. Truhlar, A product branching ratio controlled by vibrational adiabaticity and variational effects: Kinetics of the $\mathrm{H}+$ trans- $\mathrm{N} 2 \mathrm{H} 2$ reactions, J. Chem. Phys. 136 (2012) 184310. doi:10.1063/1.4707734.

[23] S.J. Klippenstein, L.B. Harding, B. Ruscic, R. Sivaramakrishnan, N.K. Srinivasan, M. Su, J. V Michael, Thermal Decomposition of $\mathrm{NH} 2 \mathrm{OH}$ and Subsequent Reactions : Ab Initio Transition State Theory and Reflected Shock Tube Experiments, J. Phys. Chem. A. 113 (2009) 10241-10259. doi:10.1021/jp905454k.

[24] http://logesoft.com/loge-software/, (n.d.).

[25] J.H. Lee, S.I. Lee, O.C. Kwon, Effects of ammonia substitution on hydrogen/air flame propagation and emissions, Int. J. Hydrogen Energy. 35 (2010) 11332-11341. doi:10.1016/j.ijhydene.2010.07.104.

[26] A. Ichikawa, A. Hayakawa, Y. Kitagawa, K.D. Kunkuma Amila Somarathne, T. Kudo, H. Kobayashi, Laminar burning velocity and Markstein length of ammonia/hydrogen/air premixed flames at elevated pressures, Int. J. Hydrogen Energy. 40 (2015) 9570-9578. doi:10.1016/j.ijhydene.2015.04.024.

[27] T. Jabbour, D.F. Clodic, Burning velocity and refrigerant flammability classification, 
ASHRAE Trans. 110 (2004) 522-533.

[28] V.F. Zakaznov, L.A. Kursheva, Z.I. Fedina, Determination of normal flame velocity and critical diameter of flame extinction in ammonia-air mixture, Combust. Explos. Shock Waves. 14 (1978) 710-713. doi:10.1007/BF00786097.

[29] U.J. Pfahl, M.C. Ross, J.E. Shepherd, K.O. Pasamehmetoglu, C. Unal, Flammability limits, ignition energy, and flame speeds in $\mathrm{H} 2-\mathrm{CH} 4-\mathrm{NH} 3-\mathrm{N} 2 \mathrm{O}-\mathrm{O} 2-\mathrm{N} 2$ mixtures, Combust. Flame. 123 (2000) 140-158. doi:10.1016/S0010-2180(00)00152-8.

[30] P.D. Ronney, Effect of Chemistry and Transport Properties on Near-Limit Flames at Microgravity, Combust. Sci. Technol. 59 (1988) 123-141. doi:10.1080/00102208808947092.

[31] P. Kumar, T.R. Meyer, Experimental and modeling study of chemical-kinetics mechanisms for H 2-NH3-air mixtures in laminar premixed jet flames, Fuel. 108 (2013) 166-176. doi:10.1016/j.fuel.2012.06.103.

[32] K. Takizawa, A. Takahashi, K. Tokuhashi, S. Kondo, A. Sekiya, Burning velocity measurements of nitrogen-containing compounds, J. Hazard. Mater. 155 (2008) 144-152. doi:10.1016/j.jhazmat.2007.11.089.

[33] Y. Li, M. Bi, B. Li, W. Gao, Explosion behaviors of ammonia-air mixtures, Combust. Sci. Technol. 190 (2018) 1804-1816. doi:10.1080/00102202.2018.1473859.

[34] P. Glarborg, J.A. Miller, B. Ruscic, S.J. Klippenstein, Modeling nitrogen chemistry in combustion, Prog. Energy Combust. Sci. 67 (2018) 31-68. doi:10.1016/j.pecs.2018.01.002. 
[35] J. Otomo, M. Koshi, T. Mitsumori, H. Iwasaki, K. Yamada, Chemical kinetic modeling of ammonia oxidation with improved reaction mechanism for ammonia/air and ammonia/hydrogen/air combustion, Int. J. Hydrogen Energy. 43 (2018) 3004-3014. doi:https://doi.org/10.1016/j.ijhydene.2017.12.066.

[36] A. Stagni, C. Cavallotti, S. Arunthanayothin, Y. Song, O. Herbinet, F. Battin-Leclerc, T. Faravelli, An experimental, theoretical and kinetic-modeling study of the gas-phase oxidation of ammonia, React. Chem. Eng. 5 (2020) 696-711. doi:10.1039/c9re00429g.

[37] J. Vandooren, J. Bian, P.J. Van Tiggelen, Comparison of experimental and calculated structures of an ammonianitric oxide flame. Importance of the $\mathrm{NH} 2+\mathrm{NO}$ reaction, Combust. Flame. 98 (1994) 402-410. doi:10.1016/0010-2180(94)90178-3.

[38] G. Dayma, P. Dagaut, Effects of air contamination on the combustion of hydrogen-effect of NO and NO2 addition on hydrogen ignition and oxidation kinetics, Combust. Sci. Technol. 178 (2006) 1999-2024. doi:10.1080/00102200600793171. 


\section{List of figure captions}

Figure 1: Laminar flame speed at 1 atm and $298 \mathrm{~K}$ for $\mathrm{NH}_{3} /$ air (a) and for stoichiometric conditions for $\mathrm{NH}_{3} / \mathrm{H}_{2}$ /air (b). Symbols: measurements from this work and published literature [2,5,10,26-30,32,33]. Dashed lines: previous model [4], solid lines: this work.

Figure 2: Integrated $\mathrm{N}$-atom mass flux analysis at $1 \mathrm{~atm}$ and $298 \mathrm{~K}$ for $\phi=1.0$ and $\phi=1.4 \mathrm{NH}_{3} /$ air blends. Numbers are the percentage of the reactant forming the respective product. Major changes in flow highlighted by red for $\phi=1.4$.

Figure 3: Laminar flame speeds of $\mathrm{NH}_{3} / \mathrm{H}_{2} /$ air at $473 \mathrm{~K}$ and 1 bar (a) and 3 bar (b) at varying $\mathrm{H}_{2}$ content. Symbols: measurements from this work. Dashed lines: previous model [4], solid lines: this work.

Figure 4: Laminar flame speed of $\mathrm{NH}_{3} / \mathrm{H}_{2} /$ air at $473 \mathrm{~K}$ and varying $\mathrm{H}_{2}$ content at $\phi=1.1$ and 510 bar. Symbols: experiments this work. Lines: simulations this work

Figure 5: Reaction sensitivity analysis for laminar flame speed of $\mathrm{NH}_{3} / \mathrm{H}_{2} /$ air at $\phi=1.0,1$ bar and $473 \mathrm{~K}$ with varying $\mathrm{H}_{2}$ content in the fuel blend.

Figure 6: Laminar flame speed of $\mathrm{NH}_{3} / \mathrm{O}_{2} / \mathrm{N}_{2}$ at 1 bar and different temperatures with varying $\mathrm{O}_{2}$ content $(21-30 \%)$. At $298 \mathrm{~K}(\mathrm{a}), 323 \mathrm{~K}$ (b) and $373 \mathrm{~K}$ (c). Symbols: measurements from this work. Lines: model prediction from this work. 
Figure 7: Reaction sensitivity analysis for laminar flame speed of $\mathrm{NH}_{3} / \mathrm{O}_{2} / \mathrm{N}_{2}$ at $\phi=1.0,1$ bar and $298 \mathrm{~K}$ with varying $\mathrm{O}_{2}$ content $(21-30 \%)$

Figure 8: Laminar flame speed of $\mathrm{NH}_{3} / \mathrm{O}_{2} / \mathrm{He}$ at 1 bar and $373 \mathrm{~K}$ and different $\mathrm{O}_{2}$ content. Symbols: this work. Lines: this work.

Figure 9: Comparison between model prediction and experimental data from literature for $\mathrm{NH}_{3} / \mathrm{O}_{2} / \mathrm{Ar}$, IDT (in ST and RCM) (a); for $\mathrm{NH}_{3} / \mathrm{NO} / \mathrm{Ar}(\phi=1.46)$, BSF (b); and for $\mathrm{H}_{2} / \mathrm{O}_{2} / \mathrm{NO}$ $(220 \mathrm{ppm}) / \mathrm{N}_{2}(\phi=0.5,10 \mathrm{~atm}, \tau=1.0 \mathrm{~s})$, JSR (c, d). Symbols: measurements [1,37,38], lines: this work. 


\section{Supporting information}

mech_Shrestha_et_al_38th_PROCI.txt - chemical kinetic mechanism

therm_Shrestha_et_al_38th_PROCI.txt - thermodata for species in the mechanism

trans_Shrestha_et_al_38th_PROCI.txt - transport data for species in the mechanism

Supporting_Information_Shrestha_et_al_38th_PROCI.pdf - additional mechanism validation figures and literature model comparison

Ammonia_Hydrogen_Flame_Speeds_Shrestha_et_al_38th_PROCI.xls - Laminar flame speed measured in this work 